\title{
MMP20 Cleaves E-Cadherin and Influences Ameloblast Development
}

\author{
John D. Bartlett ${ }^{\mathrm{a}}$ Yasuo Yamakoshi ${ }^{\mathrm{b}} \quad$ James P. Simmer ${ }^{\mathrm{b}} \quad$ Antonio Nanci $^{\mathrm{c}}$ \\ Charles E. Smith ${ }^{\text {b, d }}$

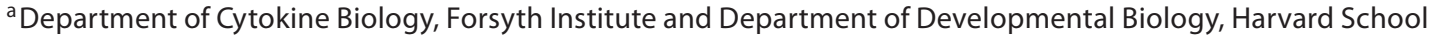 \\ of Dental Medicine, Cambridge, Mass., and ${ }^{b}$ Department of Biologic and Materials Sciences, School of Dentistry, \\ University of Michigan, Ann Arbor, Mich., USA; ${ }^{C}$ Faculté de médecine dentaire, Université de Montréal, and \\ ${ }^{d}$ Facility for Electron Microscopy Research, Department of Anatomy and Cell Biology, and Faculty of Dentistry, \\ McGill University, Montreal, Que., Canada
}

\section{Key Words}

Matrix metalloproteinases $\cdot$ Adhesion $\cdot$ Cell junctions

\begin{abstract}
Dental enamel development occurs in stages as observed by the changing morphology of the ameloblasts that are responsible for enamel formation. During the secretory stage of development, proteins including MMP20 are secreted into the enamel matrix. MMP20 is required for proper enamel formation as mutation of the Mmp20 gene causes autosomal recessive amelogenesis imperfecta. Here, we examined in detail the morphology of the Mmp20-null ameloblast cell layer. Intriguingly, we found that the Mmp20-null mouse secretory stage ameloblasts retract their Tomes' processes as if preparing to enter the maturation stage but later reextend their Tomes' processes as if resuming the secretory stage. We also demonstrated that MMP20 cleaves epithelial cadherin, i.e. E-cadherin. Cadherins are transmembrane proteins with extracellular domains that provide adhesive contacts between neighboring cells. Their intracellular domains bind to the cell cytoskeleton through catenins, including $\beta$-catenin. When specific MMPs cleave the cadherin extracellular domain, $\beta$-catenin is released and may locate to the cell nucleus as a transcription factor. Therefore, MMP20 may influence ameloblast developmental progression through hydrolysis of cadherin extracellular domains with associated release of transcription factor(s).

Copyright ๑ 2011 S. Karger AG, Basel
\end{abstract}

\section{Introduction}

The two predominant stages of enamel development are the secretory and maturation stages. The secretory stage is when the ameloblasts of the enamel organ develop protruding Tomes' processes at their apical ends and begin moving laterally in rows to form the rod and interrod enamel. These Tomes' processes are retracted as the ameloblasts transition to the maturation stage of development. Significantly, adherens junctions (AJ) were identified along the possible sliding interface between adjacent rows of secretory stage ameloblasts [Nishikawa et al., 1990].

$\mathrm{AJ}$ are composed of several classes of proteins including cadherins and catenins. Cadherins are transmembrane proteins with extracellular domains that provide important adhesive contacts between neighboring cells. The extracellular domains connect through homotypic transpairing between cadherins on adjacent cells, and the intracellular domains of cadherins are linked to the actin cytoskeleton by the catenins [reviewed in Hartsock and Nelson,

\section{Abbreviations used in this paper}

AJ adherens junction

JMD juxtamembrane domain

p120 p120-catenin

\section{KARGER}

(๑) 2011 S. Karger AG, Basel

Fax +4161306 1234

E-Mail karger@karger.ch

www.karger.com
Accessible online at: www.karger.com/cto
Dr. John D. Bartlett

Department of Cytokine Biology

Forsyth Institute

245 First Street, Cambridge, MA 02142 (USA)

Tel. +1 617892 8388, E-Mail jbartlett@ forsyth.org 
2008]. Ameloblasts express E-, N-, and P-cadherins as well as $\beta$-catenin and p120-catenin (p120), during dental enamel development [Palacios et al., 1995; Fausser et al., 1998; Obara et al., 1998; Terling et al., 1998; Sorkin et al., 2000; Heymann et al., 2002; Bartlett et al., 2010]. A major pathway for signal transduction by AJs involves the regulation of $\beta$-catenin, which can act as either a structural protein at cell-cell junctions or a transcription factor in the cell nucleus [reviewed in Munshi and Stack, 2006]. When MMPs cleave a cadherin's extracellular domain, $\beta$-catenin is removed from its position near the cell membrane and in most cases will translocate to the cell nucleus thereby promoting cell migration, cell invasion, and/or cell proliferation [Lochter et al., 1997; McGuire et al., 2003; Sanceau et al., 2003; Cowden Dahl et al., 2008; Lynch et al., 2010].

MMP20 is required for healthy dental enamel development. People and mice with homozygous MMP20 mutations have soft discolored enamel that may be hypoplastic and that easily abrades from the dentin surface [Caterina et al., 2002; Bartlett et al., 2004; Kim et al., 2005; Ozdemir et al., 2005; Bartlett et al., 2006; Papagerakis et al., 2008; Lee et al., 2010]. Herein we demonstrate that Mmp20-null mouse ameloblasts improperly progress through the secretory stage of development and that MMP20 cleaves the E-cadherin extracellular domain. These results are consistent with MMP20 playing a role in ameloblast development via cadherin hydrolysis and the subsequent release of intracellular transcription factors such as $\beta$-catenin.

\section{Materials and Methods}

All experimental procedures involving the use of animals were reviewed and approved by the Forsyth Institute and the University of Michigan Institutional Animal Care and Use Committees.

\section{Morphological Analyses}

Adult C57BL/6 mice were anaesthetized with chloral hydrate and fixed by intravascular perfusion with $1 \%$ glutaraldehyde buffered with $0.08 \mathrm{M}$ sodium cacodylate containing $0.05 \% \mathrm{CaCl}_{2}, \mathrm{pH}$ 7.2. The hemimandibles were removed and decalcified at $4{ }^{\circ} \mathrm{C}$ in $4.13 \%$ EDTA. The samples were washed and postfixed in osmium tetroxide reduced with potassium ferrocyanide, dehydrated in graded alcohols, and embedded in LR White acrylic resin (London Resin, Berkshire, UK) as previously described [Zalzal et al., 2008]. Semithin sections of incisor segments were cut with glass knives and stained with toluidine blue for examination by light microscopy (400× magnification).

\section{Preparation of Enamel Extracts}

Tooth germs of permanent molars were surgically extracted from the maxillae and mandibles of 6-month-old pigs at the
Michigan State University Meat Laboratory (East Lansing, Mich., USA). The soft, cheese-like enamel was separated from the crown with a spatula. The neutral extract (supernatant) was obtained by homogenization of the enamel samples in Sörensen buffer (made by mixing $\mathrm{Na}_{2} \mathrm{HPO}_{4}$ and $\mathrm{KH}_{2} \mathrm{PO}_{4}$ to achieve a final phosphate concentration of $50 \mathrm{mM}$ and a $\mathrm{pH}$ of 7.4), followed by centrifugation. The pellet was resuspended in carbonate buffer (made by mixing $\mathrm{NaHCO}_{3}$ and $\mathrm{Na}_{2} \mathrm{CO}_{3}$ to a final concentration of $50 \mathrm{mM}$ and a $\mathrm{pH}$ of 10.8), homogenized, and then centrifuged. The supernatant was designated as alkaline extract.

\section{Purification of Porcine MMP20}

The soft enamel-alkaline extract was fractionated by ion exchange chromatography in a Q-Sepharose ${ }^{\mathrm{TM}}$ Fast Flow column $(1.6 \times 20 \mathrm{~cm}$; GE Healthcare Biosciences, Little Chalfont, UK) equilibrated with $50 \mathrm{~mm}$ Tris- $\mathrm{HCl} / 6 \mathrm{M}$ urea $(\mathrm{pH}$ 7.4) and eluted with a linear $\mathrm{NaCl}$ gradient $(0-0.5 \mathrm{M})$. MMP20 eluted in the fourth peak was desalted and concentrated by ultrafiltration (YM-3; Millipore Corp.) and lyophilized. The lyophilized sample was dissolved with $20 \mathrm{~mm}$ sodium citrate/6 $\mathrm{M}$ urea ( $\mathrm{pH} 7.4)$ and applied to a Heparin Sepharose 6 Fast Flow column $(1.6 \times 20 \mathrm{~cm}$, GE Healthcare) equilibrated with the same buffer and eluted with a step $\mathrm{NaCl}$ gradient $(0.02,0.05$, and $0.5 \mathrm{M}$ at a flow rate of $0.2 \mathrm{ml} /$ min). MMP20 eluted in the second peak, which was buffer exchanged with $50 \mathrm{~mm}$ Tris- $\mathrm{HCl}$ ( $\mathrm{pH}$ 7.4) with a YM-3 membrane.

Digestion of the E-Cadherin Extracellular Domain by MMP20

The human E-cadherin extracellular domain (100 $\mu \mathrm{g})$ linked to the Fc IgG fragment (648-EC; R\&D Systems) was incubated in $45-\mu \mathrm{l}$ reactions with approximately $10 \mu \mathrm{g}$ of MMP-20 for $20 \mathrm{~h}$ at $37^{\circ} \mathrm{C}$ in $50 \mathrm{~mm}$ Tris- $\mathrm{HCl} / 10 \mathrm{mM} \mathrm{CaCl}_{2} / 150 \mathrm{mM} \mathrm{NaCl}$ (pH 7.4) and analyzed by SDS-PAGE and immunoblotting as described previously [Nagano et al., 2009] with a polyclonal antibody against E-cadherin (AF648, R\&D Systems) or the Fc fragment (I-9135, Sigma).

\section{Results}

Mmp20-Null Mouse Ameloblasts Can Initiate, Terminate, and Reinitiate the Secretory Stage of

Enamel Development

Secretory stage ameloblasts have a conical shaped apical protrusion termed the 'Tomes' process' that lengthens the enamel rods. Once the rods are full length and the enamel has reached its final thickness, the Tomes' process retracts and the ameloblasts progress to the maturation stage of development. Surprisingly, we found that ameloblasts in Mmp20-null mice will retract their Tomes' process during development and then later reform Tomes' processes once again. We observed this phenomenon in all 4 incisors examined which were each from 4 different Mmp20-null mice. This was not observed in incisors from Mmp20 heterozygous (1 mouse) or wild-type mice (2 mice). Figure 1a-d shows consecutive sections of an 
Fig. 1. Mmp20-null mouse ameloblasts can initiate, terminate, and reinitiate the secretory stage of enamel development. a-d Successive sections of an Mmp20-null mouse incisor. White arrows point to prominent Tomes' processes that disappear in $\mathbf{b}$ and c. $\mathbf{d}$ The arrowhead indicates the return of the Tomes' processes, with arrows indicating prominent processes. It appears that signals necessary for the ameloblasts to progress through the secretory stage are absent. Am = Ameloblast; $\mathrm{d}=$ dentin; $\mathrm{e}=$ enamel.

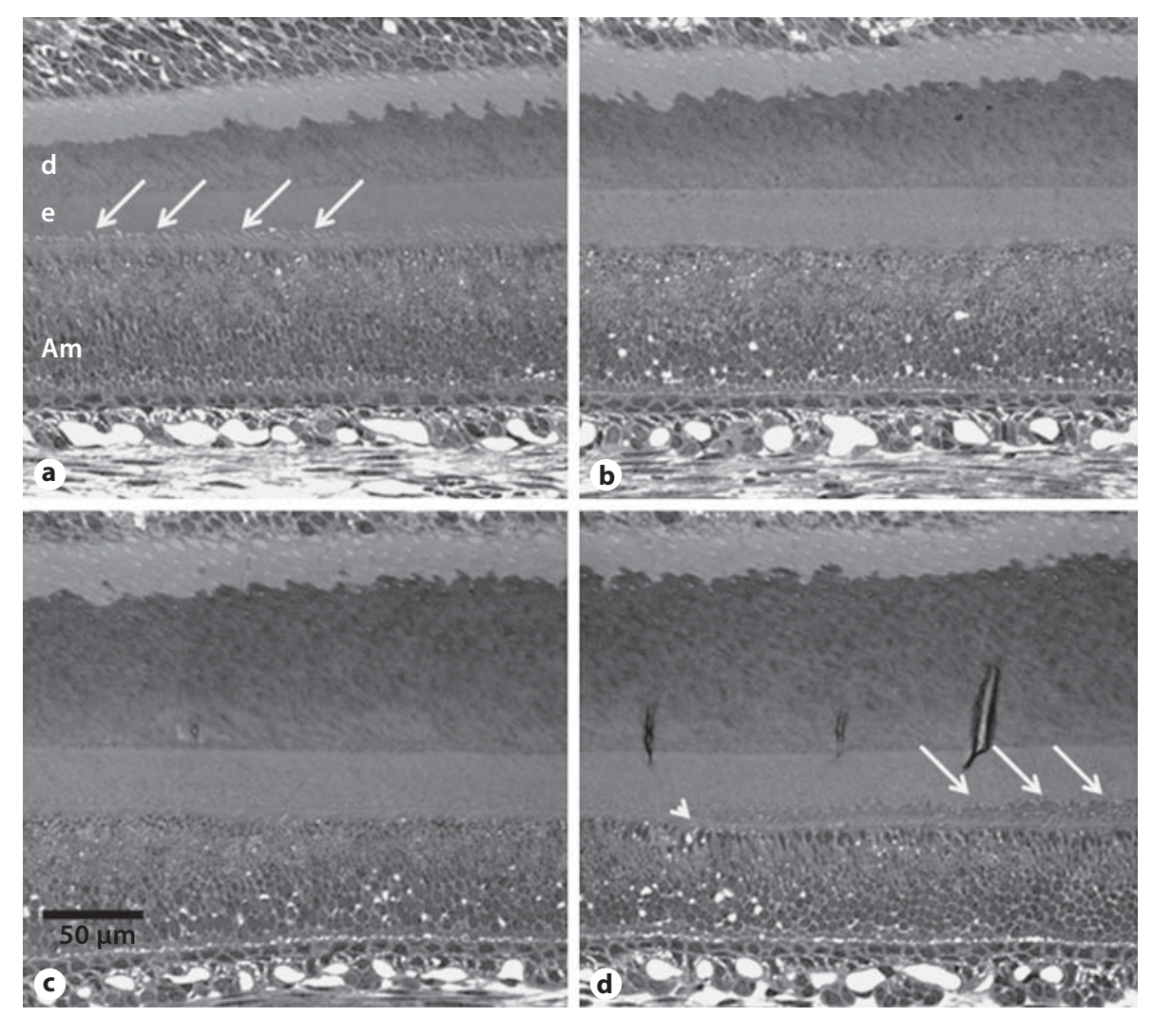

Mmp20-null secretory stage incisor. White arrows point to prominent Tomes' processes and an arrowhead in figure $1 \mathrm{~d}$ denotes the beginning of the reextension of Tomes' processes. Note that the dentin progressively thickens while the enamel does not.

\section{MMP20 Cleaves E-Cadherin}

$\beta$-catenin is part of the structure that links cadherins to the cytoskeleton. When a cadherin is cleaved by an MMP, it can release $\beta$-catenin so that it may translocate to the cell nucleus as a transcription factor. We therefore asked if MMP20 can cleave the epithelial cadherin, i.e. E-cadherin, expressed by ameloblasts during enamel formation. Purified porcine MMP20 was incubated with the recombinant human E-cadherin extracellular domain linked to the IgG Fc fragment. After $20 \mathrm{~h}$ of incubation, immunoblots specific for E-cadherin or the Fc fragment were performed. The results definitively demonstrated that MMP20 cleaves the extracellular domain of E-cadherin (fig. 2). Thus, the possibility exists that MMP20 releases intracellular signaling molecules through hydrolysis of the ameloblast E-cadherin extracellular domain.

\section{Discussion}

We provide evidence suggesting that MMP20 cleaves the extracellular domain of cadherins which may release transcription factors such as $\beta$-catenin that are important for enamel development. Faulty cell signaling may be the reason Mmp20-null ameloblasts abnormally extend, retract, and later reextend their Tomes' processes during enamel development.

Previously, we demonstrated that conditional deletion of the cadherin stabilizing molecule, p120, from epithelial tissues had a profound effect on mouse dental enamel development. p120 binds to an intracellular cadherin domain near the cell membrane termed the 'juxtamembrane domain' (JMD). Mutation of the E-cadherin JMD demonstrated that p120-E-cadherin interaction was required for high-level cell adhesiveness [Thoreson et al., 2000; Ferber et al., 2002], and it was also shown that the binding of p120 to the JMD prevents cadherins from becoming internalized and degraded [Davis et al., 2003; Xiao et al., 2003; Maeda et al., 2006]. When p120 was deleted from epithelial tissues, the general shape of the teeth was normal. However, the resulting dental enamel had no rod pattern 


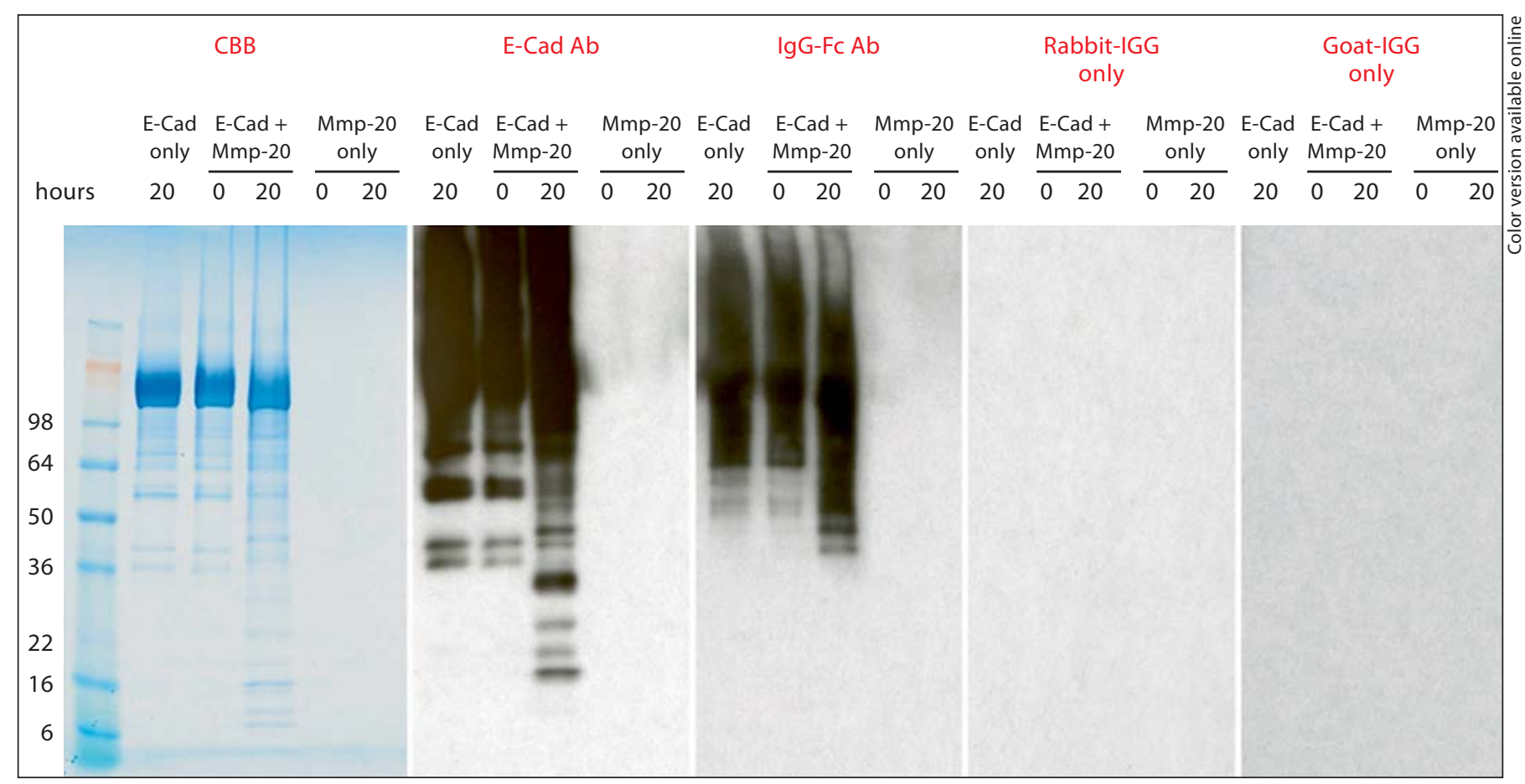

Fig. 2. Immunoblot showing that MMP20 cleaves the E-cadherin extracellular domain. The recombinant human E-cadherin/Fc chimera that links the E-cadherin extracellular domain to an $\mathrm{Fc}$ fragment was incubated with MMP20 that was purified from porcine enamel. Incubations were for 0 or $20 \mathrm{~h}$ followed by immu- noblotting with primary antisera specific for E-cadherin or the linked Fc fragment. The secondary antiserum was from rabbit (for IgG-Fc Ab) or goat (for E-Cadherin Ab). Also shown is an SDS-PAGE gel stained for protein and 2 negative control immunoblots that were treated with only the secondary antisera. and had a very rough surface composed of mineralized spherical structures, and this enamel easily abraded from the tooth surface [Bartlett et al., 2010]. Therefore, stabilization of cadherins to the cell surface is essential for dental enamel formation and this suggests that the hydrolysis of cadherin contacts necessary for ameloblast migration and signaling may also be of importance in enamel formation.

Here we demonstrate that Mmp20-null ameloblasts have abnormal extension and retraction of their Tomes' processes and therefore seem unable to maintain normal linear continuity of appositional growth during the secretory stage of amelogenesis. We also show that MMP20 can cleave an important epithelial cadherin and that this hydrolysis may have important cell signaling functions.

\section{Acknowledgements}

This work was funded by NIDCR grants DE016276 (J.D.B.) and DE019775 (J.P.S.) and by the CIHR (A.N.).

\section{References}

Bartlett, J.D., E. Beniash, D.H. Lee, C.E. Smith (2004) Decreased mineral content in MMP20 null mouse enamel is prominent during the maturation stage. J Dent Res 83: 909-913.

Bartlett, J.D., J.M. Dobeck, C.E. Tye, M. PerezMoreno, N. Stokes, A.B. Reynolds, E. Fuchs, Z. Skobe (2010) Targeted p120-catenin ablation disrupts dental enamel development. PLoS One 5: e12703.
Bartlett, J.D., Z. Skobe, D.H. Lee, J.T. Wright, Y. Li, A.B. Kulkarni, C.W. Gibson (2006) A developmental comparison of matrix metalloproteinase-20 and amelogenin null mouse enamel. Eur J Oral Sci 114(suppl 1): 18-23.

Caterina, J.J., Z. Skobe, J. Shi, Y. Ding, J.P. Simmer, H. Birkedal-Hansen, J.D. Bartlett (2002) Enamelysin (matrix metalloproteinase 20)-deficient mice display an amelogen- esis imperfecta phenotype. J Biol Chem 277: 49598-49604.

Cowden Dahl, K.D., J. Symowicz, Y. Ning, E. Gutierrez, D.A. Fishman, B.P. Adley, M.S. Stack, L.G. Hudson (2008) Matrix metalloproteinase 9 is a mediator of epidermal growth factor-dependent e-cadherin loss in ovarian carcinoma cells. Cancer Res 68: 4606-4613. 
Davis, M.A., R.C. Ireton, A.B. Reynolds (2003) A core function for p120-catenin in cadherin turnover. J Cell Biol 163: 525-534.

-Fausser, J.L., O. Schlepp, D. Aberdam, G. Meneguzzi, J.V. Ruch, H. Lesot (1998) Localization of antigens associated with adherens junctions, desmosomes, and hemidesmosomes during murine molar morphogenesis. Differentiation 63: 1-11.

Ferber, A., C. Yaen, E. Sarmiento, J. Martinez (2002) An octapeptide in the juxtamembrane domain of VE-cadherin is important for p120ctn binding and cell proliferation. Exp Cell Res 274: 35-44.

-Hartsock, A., W.J. Nelson (2008) Adherens and tight junctions: structure, function and connections to the actin cytoskeleton. Biochim Biophys Acta 1778: 660-669.

-Heymann, R., I. About, U. Lendahl, J.C. Franquin, B. Obrink, T.A. Mitsiadis (2002) E- and $\mathrm{N}$-cadherin distribution in developing and functional human teeth under normal and pathological conditions. Am J Pathol 160: 2123-2133.

Kim, J.W., J.P. Simmer, T.C. Hart, P.S. Hart, M.D. Ramaswami, J.D. Bartlett, J.C. Hu (2005) MMP-20 mutation in autosomal recessive pigmented hypomaturation amelogenesis imperfecta. J Med Genet 42: 271-275.

Lee, S.K., F. Seymen, H.Y. Kang, K.E. Lee, K. Gencay, B. Tuna, J.W. Kim (2010) MMP20 hemopexin domain mutation in amelogenesis imperfecta. J Dent Res 89: 46-50.

Lochter, A., S. Galosy, J. Muschler, N. Freedman, Z. Werb, M.J. Bissell (1997) Matrix metalloproteinase stromelysin-1 triggers a cascade of molecular alterations that leads to stable epithelial-to-mesenchymal conversion and a premalignant phenotype in mammary epithelial cells. J Cell Biol 139: 1861-1872.
Lynch, C.C., T. Vargo-Gogola, L.M. Matrisian, B. Fingleton (2010) Cleavage of E-cadherin by matrix metalloproteinase-7 promotes cellular proliferation in nontransformed cell lines via activation of RhoA. J Oncol 2010: 530745.

Maeda, M., E. Johnson, S.H. Mandal, K.R. Lawson, S.A. Keim, R.A. Svoboda, S. Caplan, J.K. Wahl 3rd, M.J. Wheelock, K.R. Johnson (2006) Expression of inappropriate cadherins by epithelial tumor cells promotes endocytosis and degradation of E-cadherin via competition for p120(ctn). Oncogene 25: 4595-4604.

McGuire, J.K., Q. Li, W.C. Parks (2003) Matrilysin (matrix metalloproteinase-7) mediates E-cadherin ectodomain shedding in injured lung epithelium. Am J Pathol 162: 1831-1843.

-Munshi, H.G., M.S. Stack (2006) Reciprocal interactions between adhesion receptor signaling and MMP regulation. Cancer Metastasis Rev 25: 45-56.

Nagano, T., A. Kakegawa, Y. Yamakoshi, S. Tsuchiya, J.C. Hu, K. Gomi, T. Arai, J.D. Bartlett, J.P. Simmer (2009) Mmp-20 and Klk4 cleavage site preferences for amelogenin sequences. J Dent Res 88: 823-828.

Nishikawa, S., S. Tsukita, S. Sasa (1990) Localization of adherens junction proteins along the possible sliding interface between secretory ameloblasts of the rat incisor. Cell Struct Funct 15: 245-249.

-Obara, N., Y. Suzuki, Y. Nagai, M. Takeda (1998) Expression of E- and P-cadherin during tooth morphogenesis and cytodifferentiation of ameloblasts. Anat Embryol (Berl) 197: 469-475.

Ozdemir, D., P.S. Hart, O.H. Ryu, S.J. Choi, M. Ozdemir-Karatas, E. Firatli, N. Piesco, T.C. Hart (2005) MMP20 active-site mutation in hypomaturation amelogenesis imperfecta. J Dent Res 84: 1031-1035.
Palacios, J., N. Benito, R. Berraquero, A. Pizarro, A. Cano, C. Gamallo (1995) Differential spatiotemporal expression of $\mathrm{E}$ - and $\mathrm{P}$-cadherin during mouse tooth development. Int J Dev Biol 39: 663-666.

Papagerakis, P., H.K. Lin, K.Y. Lee, Y. Hu, J.P. Simmer, J.D. Bartlett, J.C. Hu (2008) Premature stop codon in MMP20 causing amelogenesis imperfecta. J Dent Res 87: 56-59.

Sanceau, J., S. Truchet, B. Bauvois (2003) Matrix metalloproteinase- 9 silencing by RNA interference triggers the migratory-adhesive switch in Ewing's sarcoma cells. J Biol Chem 278: 36537-36546.

Sorkin, B.C., M.Y. Wang, J.M. Dobeck, K.L. Albergo, Z. Skobe (2000) The cadherin-catenin complex is expressed alternately with the adenomatous polyposis coli protein during rat incisor amelogenesis. J Histochem Cytochem 48: 397-406.

Terling, C., R. Heymann, B. Rozell, B. Obrink, J. Wroblewski (1998) Dynamic expression of E-cadherin in ameloblasts and cementoblasts in mice. Eur J Oral Sci 106(suppl 1): 137-142.

Thoreson, M.A., P.Z. Anastasiadis, J.M. Daniel, R.C. Ireton, M.J. Wheelock, K.R. Johnson, D.K. Hummingbird, A.B. Reynolds (2000) Selective uncoupling of p120(ctn) from Ecadherin disrupts strong adhesion. J Cell Biol 148: 189-202.

Xiao, K., D.F. Allison, K.M. Buckley, M.D. Kottke, P.A. Vincent, V. Faundez, A.P. Kowalczyk (2003) Cellular levels of p120 catenin function as a set point for cadherin expression levels in microvascular endothelial cells. J Cell Biol 163: 535-545.

Zalzal, S.F., C.E. Smith, A. Nanci (2008) Ameloblastin and amelogenin share a common secretory pathway and are co-secreted during enamel formation. Matrix Biol 27: 352-359. 